\title{
Primary MDR Tuberculosis Scrofula- Awareness for the Treating Physicians
}

\author{
Ashok Kumar Aradhyula1, Sowmitha Shankar Gangadharan², Gangadharan Vadivelu³, Gayathri Ganapathy4, \\ Anbumaran Parivakkam Mani ${ }^{5}$
}

${ }^{1}$ Department of Pulmonary Medicine, Saveetha Medical College and Hospital, Saveetha University, Kuthambakkam, Tamilnadu, India. 2Department of Pulmonary Medicine, Saveetha Medical College and Hospital, Saveetha University,

Kuthambakkam, Tamilnadu, India. ${ }^{3}$ Department of Pulmonary Medicine, Saveetha Medical College and Hospital,

Saveetha University, Kuthambakkam, Tamilnadu, India. ${ }^{4}$ Department of Pulmonary Medicine, Saveetha Medical College and Hospital, Saveetha University, Kuthambakkam, Tamilnadu, India. ${ }^{5}$ Department of Pulmonary Medicine, Saveetha Medical College and Hospital, Saveetha University, Kuthambakkam, Tamilnadu, India.

\section{PRESENTATION OF CASE}

A 48-year-old female patient presented to OPD with swelling on the nape of the neck (right side) since 1 month and discharging sinus since 1 day with no constitutional symptoms like loss of appetite, loss of weight, or fever. She gave history of treatment for similar swelling \& discharge on the back and right side of the neck for which she was treated with category 1 ATT for 6 months with good response. Now presented within 1 month with above presentation to our OPD.

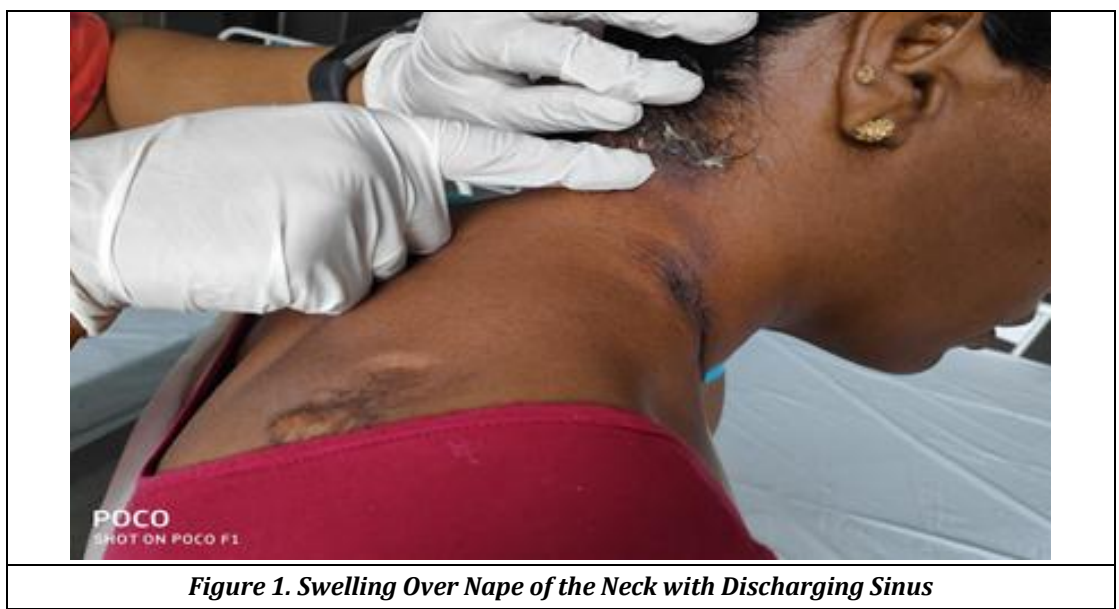

Examination revealed swelling of $5^{*} 6 \mathrm{cms}$ with discharging sinus on nape of neck with multiple healed lesions in the right cervical region and suprascapular region. Systemic examination was normal.
Corresponding Author:

Ashok Kumar Aradhyula,

13/5, Kunjitham Guruswamy Street,

Ayanavaram, Chennai,

Tamilnadu, India.

E-mail: chestvrach@gmail.com

DOI: $10.14260 /$ jemds/2019/784

Financial or Other Competing Interests: None.

How to Cite This Article:

Aradhyula AK, Gangadharan SS, Vadivelu G, et al. Primary MDR tuberculosis scrofulaawareness for the treating physicians. J. Evolution Med. Dent. Sci. 2019;8(48):36353636, DOI: 10.14260/jemds/2019/784

Submission 14-09-2019,

Peer Review 11-11-2019,

Acceptance 18-11-2019,

Published 02-12-2019.

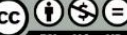




\section{CLINICAL DIAGNOSIS}

Relapse of tuberculous adenitis.

\section{DIFFERENTIAL DIAGNOSIS}

There are numerous causes of peripheral lymphadenopathy. This list includes reactive lymphadenitis, [secondary to viral and bacterial infections], TB lymphoma, sarcoidosis, secondary carcinoma and uncommon causes like fungal diseases, toxoplasmosis and diseases of the reticuloendothelial system among others.[1]

\section{PATHOLOGICAL DISCUSSION}

Investigations- $\mathrm{Hb}$ - 9.4, ESR- $110 \mathrm{~mm} / \mathrm{hr}$., chest X-ray- clear, FNAC of the node \& pus sent for analysis, Pus for AFB- positive for AFB. Pus for Gene Xpert- MTB detected, rifampicin resistance detected. Cytology- consistent with tuberculous lymphadenitis.

The most common anatomical sites affected by extrapulmonary TB are lymph nodes, pleura, bone and joints, urogenital tract, and meninges.[2] There is limited information in the literature regarding prevalence of drug resistance in EPTB especially from high burden settings like India..[3] The World Health Organization (WHO) has reported a 52\% cure rate for drug resistance $\mathrm{TB}$ which is much lower than that for drug-sensitive TB. ${ }^{[4]}$ In this case diagnosis of primary MDR tuberculous adenitis was made and patient was started on shorter MDR regimen with good clinical response within 3 months. In 2016, WHO endorsed and recommended a shorter MDR-TB regimen for 9-11 months duration based on growing evidences of its effectiveness to improve treatment success particularly in RR-TB patients.[5] this regimen have been reported to achieve relapse-free cure in over $85 \%$ of cases even under programmatic conditions.[6] Molecular testing for drug resistance culture is done for all pulmonary tuberculosis. The same principle must be employed for diagnosing extrapulmonary tuberculosis also. Every attempt should be made to rule out MDR tuberculosis either primary or secondary in all extra pulmonary tuberculosis, from the specimen like pus, fluid, FNAC material and biopsy specimen. In this patient in her first visit if pus \& FNAC material had been sent for molecular testing by her treating physician she would have been diagnosed as primary MDR TB and would have been initiated on MDR regimen. So, following the principle of sending all extra pulmonary samples to molecular testing will avoid wasted resources, time \& morbidity and also help us to achieve the goal of TB free India by 2025. Hence all treating physicians to be aware of such presentation in extrapulmonary tuberculosis also and every effort should be taken by to diagnose MDR-TB in extrapulmonary tuberculosis at the earliest for a better outcome.

\section{DISCUSSION OF MANAGEMENT}

Patient was started on shorter MDR regimen with good clinical response within 3 months.

FINAL DIAGNOSIS

Primary MDR tuberculous adenitis.

\section{REFERENCES}

[1] Mohan A, Reddy MK, Phaneendra BV, et al. Aetiology of peripheral lymphadenopathy in adults: analysis of 1724 cases seen at a tertiary care teaching hospital in southern India. Natl Med J India 2007;20(2):78-80.

[2] Solovic I, Jonsson J, Korzeniewska-Koseła $M$, et al. Challenges in diagnosing extrapulmonary tuberculosis in the European Union, 2011. Euro Surveill 2013;18(12):20432.

[3] Maurya AK, Kant S, Nag VL, et al. Trends of antituberculosis drug resistance pattern in new cases and previously treated cases of extrapulmonary tuberculosis cases in referral hospitals in northern India. J Postgrad Med 2012;58(3):185-9.

[4] WHO. Multi-Drug Resistant Tuberculosis (MDR-TB) 2016 Update.

http://www.who.int/tb/challenges/mdr/mdr_tb_factsh eet.pdf?ua=1.

[5] WHO treatment guidelines for drug-resistant tuberculosis, 2016 update. Geneva: World Health Organization, $2016 \quad$ (WHO/HTM/TB/2016.4; http://apps.who.int/iris/bitstream/10665/250125/1/9 789241549639-eng.pdf, accessed 15 February 2019).

[6] WHO treatment guidelines for drug-resistant tuberculosis, 2016 update. Geneva: World Health Organization, 2016. (WHO/HTM/TB/2016.4;http://apps.who.int/iris/bitstre am/10665/250125/1/9789241549639-eng.pdf, accessed 15 February 2019). 